\title{
MAKNA SIMBOLIK TRADISI MONDHOSIO DI DUSUN PANCOT, KALISORO, TAWANGMANGU, KARANGANYAR
}

\author{
Aprilia Ika Nur Janah \\ Aqidah dan Filsafat Islam, Institut Agama Islam Negeri Surakarta \\ apriliaikanur7@gmail.com
}

\begin{abstract}
Abstrak
Artikel ini bertujuan untuk mengungkap makna di balik tradisi bersih desa di daerah Kalisoro, Tawangmangu, Karanganyar, Jawa Tengah. Tradisi bersih desa memang banyak dilaksanakan di berbagai daerah di Jawa. Akan tetapi, ada hal unik yang terjadi di daerah Tawangmangu ini. Selain karena tempat yang terkenal dengan basis wisata, masyarakat di dalamnya memang terdiri dari ragam kepercayaan. Penelitian ini menggunakan pendekatan kualitatif deskriptif yang memaparkan sejumlah hasil wawancara dan observasi lapangan. Hasil penelitian ini memperlihatkan bahwa kegiatan bersih desa ini, bahwa ada tradisi mondhosio yang di satu sisi menampilkan upacara sesaji kepada roh (dayang) desa setempat, namun di sisi lain ada nuansa islami yang muncul di sana. Nuansa islami itu ditunjukkan dengan ungkapan nadzar, dan simbol-simbol lain seperti sedekah dan do'a-do'a kebaikan. Hal ini menunjukkan bahwa tradisi mondhosio yang telah ada sejak lama mengalami akulturasi dengan perkembangan zaman dan melampaui keyakinan kejawen yang mereka miliki. Sehingga kajian ini menjadi menarik untuk dilakukan dan menjadi salah satu warisan kearifan lokal sebagai bagian dari kekayaan keragaman masyarakat Indonesia.
\end{abstract}

Kata Kunci: Mondhosio, Bersih Desa, Simbol, Kearifan Lokal

\begin{abstract}
This article aims to explore the meaning behind the tradition of bersib desa in the Kalisoro, Tawangmangu, Karanganyar, Central Java. Bersib desa is indeed widely practiced in various regions in Java. However, there are unique things happening in this Tawangmangu area. apart from being a place famous for its tourist base, the people in it are indeed made up of various beliefs. This study uses a descriptive qualitative approach that describes the results of interviews and field observations. The results of this study show that the activities of bersib desa, there is a mondhosio tradition which on one side presents offerings to the spirit of the local village, but on the other hand there is an Islamic nuance that appears there. Islamic nuances are indicated by votive expressions, and other symbols such as alms and good wishes. This shows that the mondhosio tradition has existed for experienced acculturation with the times and exceeded their Javanese beliefs. This study becomes interesting to do and become one of the legacies of local wisdom as part of the rich diversity of Indonesian society.
\end{abstract}

Keywords: Mondhosio, Bersih desa, Symbol, Local Wisdom 


\section{Pendahuluan}

Indonesia adalah negara yang memiliki keragaman suku, budaya, adat dan tradisi yang sangat luas. Keragaman tersebut ditunjukkan dengan adanya ciri khas di setiap daerahnya. Meskipun jaman telah banyak berubah, namun tradisi-tradisi di berbagai wilayah di Indonesia masih tetap dilestarikan oleh generasi penerus. ${ }^{1}$ Memang, harus diakui bahwa jaman pula yang membuat masyarakat mengalami pasang surut keyakinan dalam melaksanakan tradisi. Akan tetapi, di banyak wilayah Indonesia, tradisi pelaksanaan upacara-upacara adat masih berlangsung dengan baik. $^{2}$

Salah satu tradisi di Jawa yang masih banyak dilakukan oleh masyarakat hingga saat ini adalah bersih desa. ${ }^{3}$ Bersih desa merupakan upacara adat Jawa yang masih dilakukan oleh masyarakat sebagai ungkapan rasa syukur kepada Tuhan atas nikmat yang diberikan. Dalam banyak tempat, tradisi bersih desa ini dilakukan oleh banyak orang atau kelompok, dan bukan kegiatan individu.

Sejauh ini, tradisi bersih desa yang ada di berbagai wilayah cukup menyita perhatian para sarjana untuk mengkajinya. Misalnya, Dara Maytisa yang meneliti tentang tabayun dan bersih desa di Wonogiri. Tabayun di sini diartikan sebagai bentuk terima kasih dan suatu pengharapan keselamatan setelah panen padi. Dalam penelitiannya Dara juga menekankan pada fungsi tabayun dalam bersih desa. Menurutnya, fungsi dari bersih desa tak lain untuk meningkatkan solidaritas sosial yang tinggi di desa tersebut. Solidaritas ini diwujudkan dalam berbentuk kerja bakti membersihkan dusun, rewang, kondangan atau kenduri.

Selain fungsi solidaritas, tradisi bersih desa juga memiliki ragam cara perayaannya. Ada yang menggunakan sesaji, sedekah, ada juga yang menggunakan kesenian. Hasil kajian Rita Fitriana memotret aspek fungsi kesenian dengan meanmpilkan simbol raksasa pada acara bersih desa di daerah Binangun, Blitar, Jawa Timur. Menurutnya, fungsi dari kesenian raksasa dalam acara bersih desa tersebut bermakna sebagai perlakuan secara simbolik untuk memulihkan tata alam dan menempatkan manusia dalam tata alam. ${ }^{4}$

Penelitian lain tentang bersih desa desa dilakukan oleh Sherly Cathrin yang meneliti upacara bersih desa di daerah Tawun, Kecamatan Kasreman, Ngawi, Jawa Timur. Tradisi bersih desa ini

1 Abdullah Yusof, "Relasi Islam dan Budaya Lokal Studi Tentang Tradisi Nyadran Di Desa Sumogawe Kecamatan Getasan Kabupaten Semarang,” Kontemplasi 04, no. 01 (2016): 53-55.

${ }^{2}$ Rikza Fauzan and Nashar, "Mempertahankan Tradisi, Melestarikan Budaya; Kajian Historis Dan Nilai Budaya Lokal Kesenian Terebang Gede Di Kota Serang," Candrasangkala 3, no. 1 (2017): 1-3.

3 Ali Sobirin, "Studi Pelaksanaan Upacara Bersih Desa Pranggang Kecamatan Plosoklaten Kabupaten Kediri,” 2017. Lihat juga. Safrudin Aziz, “ Tradisi Pernikahan Adat Jawa Keraton Membentuk Keluarga Sakinah,” Kebudayaan Islam 15, no. 1 (2017): 22-41.

${ }^{4}$ Rita Fitriana, "Bentuk Dan Fungsi Kesenian Raksasa Dalam Upacara Bersih Desa Di Desa Salamrejo Kecamatan Binangun Kabupaten Blitar” (Institut Seni Indonesia, Surakarta, 2017). 
merupakan upacara pembersihan sandhang kolam alam yang dianggap keramat. Dengan menggunakan analisis hermeneutic filosofis, Sherly mengatakan bahwa bersih desa ini dilakukan sebagai rasa syukur pada Tuhan dan hormat pada Ki Ageng Matawun yang merupakan pendiri Desa Tawun, dan roh Ki Ageng dianggap masih ada dan menjaga desa tersebut. ${ }^{5}$ Jika model perayaannya dengan menggunakan istilah sesaji, biasanya terjadi pergolakan di masyarakat. Ada yang menerima dengan pemaknaan positif, namun ada juga yang menolaknya karena dianggap sebagai perilaku syirik, dan sebagainya. ${ }^{6}$ Di beberapa tempat model pemaknaan terhadap upacara ini banyak mengalami pergeseran dengan model akulturasi budaya. Banyak yang telah menyadari bahwa dahulu model sesaji yang dipersembahkan untuk dayang desa kini doa dan tujuannya adalah untuk sedekah dan mengaharap pertolongan dari Tuhan.?

Bersamaan dengan hal itu, di daerah Pancot, Kalisoro, Tawangmangu, Karanganyar, Jawa Tengah hingga saat ini juga masih sering berlangsung tradisi bersih desa yang terkenal dengan nama Mondhosio. Dalam tradisi ini, terdapat acara lempar tangkap ayam ini yang dilakukan sebagai nazar dari warga dusun Pancot atau warga lain. Kegiatan ini hanya ada di dua dusun, salah satunya adalah dusun Pancot. Bentuk kegiatan ini, nampaknya cukup menyita perhatian warga dari beberapa daerah sekitarnya. Sehingga menarik untuk dikaji lebih lanjut tentang prosesi dan makna di dalam prosesi bersih desa di daerah ini, sebagai bagian dari upaya untuk melacak keragaman budaya Indonesia yang beragam.

Kajian ini menggunakan metode kualitatif untuk penggalian datanya. Selanjutnya, dalam kajian ini akan terlebih dahulu digambarkan proses pelaksanaan kegiatan bersih desa dan tradisi mondhosio. ${ }^{8}$ Teknik wawancara (interview) dengan beberapa informan kunci juga dilakukan dalam penelitian ini. Selain itu observasi juga penting dilakukan, tidak terbatas pada orang, melainkan dengan suatu objek alam juga.

\section{Sejarah Tradisi Mondhosio}

Peringatan bersih desa, biasanya berangkat dari sebuah cerita rakyat yang beragam dengan kebenaran yang bisa diperdebatkan. Dalam hal ini, Mondhosio sama halnya dengan bersih desa yang lain. Menurut cerita rakyat dan cerita pewayangan, mondhosio diambil dari wuku kelahiran dusun Pancot yang lahir pada hari Selasa Kliwon wuku Mondhosio. Cerita ini memiliki memiliki

\footnotetext{
5 Sherly Chatrin, “Tinjauan Filsafat Kebudayaan Terhadap Upacara Adat Bersih Desa Di Desa Tawun, Kecamatan Kasreman, Kabupaten Ngawi Jawa Timur," Jurnal Filsafat UGM 27, no. 1 (2017): 30-63.

${ }^{6}$ Idham Rizkiawan, "Faktor-Faktor Yang Mempengaruhi Persepsi Masyarakat Tentang Makna Sesajen Pada Upacara Bersih Desa,” Boga 5, no. 2 (2017): 11-17.

7 M. Aly Haidar, "Pergeseran Pemaknaan Ritual 'Merti Dusun'; Studi Atas Ritual Warga Dusun Celengan, Tuntang, Semarang," Al A'raf: Jurnal Pemikiran Islam dan Filsafat 13, no. 1 (2016): 1-24.

${ }^{8}$ Sugiyono, Metode Penelitian Kuantitatif, Kualitatif, Dan R \& D (Bandung: Alfabeta, 2016).

${ }^{9}$ Choerul Anam, "Tradisi Sambatan Dan Nyadran Di Dusun Suruhan," sabda 12 (2017): 77-84.
} 
perbedaan dengan cerita lain tentang Prabu Boko, konon cerita rakyat tentang Prabu Boko yang memiliki kerajaan yang bernama Negeri Medang Kamulyan atau Medang Kamulan. Negeri ini memiliki Rakyat yang ayem tentrem, loh jinawi, rakyatnya yang memiliki kehebatan.

Suatu ketika garwa (istri) Prabu Boko sedang memasak hidangan untuk Prabu Boko. Tibatiba jarinya terkena pisau dan kemudian sedikit daging dan darahnya masuk kedalam makanan tersebut. Hidangan tersebut kemudian diberikan kepada Prabu Boko. Merasakan makanan yang lezat, kemudian bertanya kepada sang istrinya. Istrinya pun cerita kalau masakannya yang dia olah terkena darah dan sedikit dagingnya yang masuk kemakanan tersebut. Seketika Prabu Boko timbul pemikiran bahwa makan daging manusia yang rasanya sangat enak, makan sedikit darah dan dagingnya saja enaknya seperti ini apalagi makan seluruh daging manusianya. Setelah itu, Prabu Boko sekarang menjadi manusia Kanibal yaitu manusia yang suka makan dagingnya manusia. maka dari itu setiap Selasa kliwon Prabu Boko ini meminta Upeti atau pajak dari manusia untuk dijadikan santapan Prabu Boko.

Masyarakat yang dulunya ayem, tentrem, damai yang kemudian menjadi masyarakat yang ketakutan karena selama masih hidup, mereka akan dimangsa oleh Prabu Boko. Suatu saat giliran upeti manusia sampai ke rumah 'Mbok Rondho Dhadapan'. Selasa kliwon yang akan datang anak Mbok Rondho Dhadapan ini akan dijadikan pajak untuk Prabu Boko. Mbok Rondho Dhadapan pun setiap hari menangis karena anak satu-satunya akan dijadikan mangsa untuk Prabu Boko. ${ }^{10}$

Konon, ada satriya Pringgondani yang bernama Putut Tetuko yang sedang turun dari Pringgondani kemudian lewat depan Rumah Mbok Rondho Dhadapan. Ketika sedang lewat, Putut Tetuko mendengar bahwa Mbok Rondho Dhadapan selalu menangis. Ia kemudian mencari informasi kenapa setiap lewat di depan rumahnya Mbok Rondho selalu menangis. Kemudian Putut Tetuko itu datang dan menemui Mbok Rondho dan anaknya tidak jadi dijadikan pajak untuk Prabu Boko, karena sudah digantikan oleh Putut Tetuko.

Pada Selasa Kliwon dari Dhadapan Putut Tetuko diiringi sampai ke halaman Bale Patokan. Terjadi pertempuran antara Putut Tetuko dengan Prabu Boko. Karena sama-sama saktinya, Putut Tetuko, di belah dengan pedang pun tidak mati. Bahkan dimakan oleh Prabu Boko pun tidak Mati. Putut Tetuko di sembur atau dikeluarkan dari mulut Prabu Boko sampai ke pantai selatan. Kemudian suatu hari Putut Tetuko kembali ke Bale Pathokan dan kemudian membawa Batu Gilang. Pertempuran pun masih berlanjut antara Putut Tetuko dan Prabu Boko. Pada akhirnya kepala Prabu Boko di banting di Batu Gilang dan kemudian kepalanya di pancat (kepalanya diangkat dan kemudian dipancat dengan kaki Putut Tetuko) maka desa Pancot itu berasal dari kata Pancat.

${ }^{10}$ Wawancara Pribadi dengan Radianto, 10 Maret 2020. 
Pertempuran berakhir pada hari selasa kliwon wukunya wuku mondhosio. Matinya Prabu Boko di hari Selasa Kliwon di tengarahi bahwa sima angkoro murko Prabu Boko. Untuk memperingati kejadian itu, dilakukan syukuran Dusun Pancot yang sudah terbebas dari Prabu Boko yang meminta upeti atau pajak daging manusia. Hingga saat ini, setiap tujuh bulan sekali diperingati hari lahirnya Dusun Pancot dan sebagai rasa syukur atas lenyapnya Prabu Boko. ${ }^{11}$

\section{Prosesi Bersih Desa}

Prosesi Tradisi bersih desa dimulai dua hari sebelum Selasa kliwon yaitu pada hari Minggu Pon dan Senin Wage. Acara persiapan sudah dimulai pada hari Rabu Pon pagi, warga masyarakat bergotong royong untuk membuat air badheg (air yang terbuat dari ketan dan hanya diambil airnya saja). Kemudian air tersebut disimpan dari rumah sesepuh desa atau kepala desa. Penyimpanan air ini bertujuan untuk disiramkan ke Batu Gilang.

Tata upacara ini dimulai pada hari Minggu pon. Dua hari sebelum puncak tradisi Mondhosio berlangsung, warga setempat mulai mempersiapkan beberapa bahan-bahan yang diperlukan untuk sesajen. Warga mengumpulkan peralatan atau yang disebut dengan istilah Cebuan yakni dengan mengumpulkan beras dan uang 15.000, kayu, kelapa dan lain-lain. Cebuan ini ditarik bagi semua warga Dusun Pancot. Beras yang sudah dikumpulkan dari warga kemudian untuk membuat makanan yang disebut dengan makanan ghandik. Dalam istilah masyarakat desa lain disebut makanan Jadah yang terbuat dari ketan. Bedanya, gandhik terbuat dari beras, dan kemudian dibentuk seperti punggung sapi.

Kemudian dilanjut pada hari senin pagi, ibu-ibu memasak sesaji termasuk membuat gandhik. Pelaksanaan ini dilaksankan pada senin pagi sampai selesai bahkan sampai larut malam. Dalam masak sesaji ataupun gandhik, ibu-ibu dipersyaratkan tidak boleh dalam keadaan haid atau nifas. Mereka harus suci dari hadast dan bersih. Ketika memasak, juga tidak boleh berbicara kotor, harus sopan, dan mengedepankan tata krama. Alat untuk memasak di Bale Pathokan, masih menggunakan alat-alat tradisional, dan tidak menggunakan kompor. Sehingga, proses memasak menggunakan kayu bakar, yang semua dilakukan dengan sopan, dengan tangan kanan dan sebagainya. Bahkan, kayu bakar tidak boleh dilompati oleh kaki. Makanan yang dimasak pun tidak boleh dicicipi sedikitpun. Kemudian, makanan yang sudah selesai dimasak, disimpan di rumah sesepuh adat.

Pada malam selasa kliwon, beberapa orang perangkat adat menabuh 'Bendhe'. Bandhe adalah serupa dengan alat bunyi penanda. Ia tidak boleh dibunyikan oleh sembarang orang, dan bunyinya diarahkan ke sembilan tempat yang dianggap keramat, seperti Punden Bale Pathokan, Cikal Bakal,

11 Wawancara Pribadi, Selasa, 10 Maret 2020. 
Kembang Sore, Gompong, Pringgondani, Mbok Rondho Dhadapan, Pojok Kidul, Perempatan, Mbakalan, dan kemudian diarahkan untuk mengelilingi Dusun Pancot. Bandhe dibunyikan sebagai woro-woro (pemberian informasi), makhluk halus, untuk memberitahu bahwa hari ini akan melakukan acara Mondhosio. Kemudian meminta doa kepada Tuhan, dan doa para leluhur agar pelaksanaan mondhosio berjalan dengan lancar. Menjelang tengah malam diadakan tirakatan yang diadakan di rumah adat setempat. Tirakatan ini merupakan sebuah renungan agar acara yang dilakukan esok berjalan lancar dan para danyang-danyang merestui upacara tersebut.

Puncak upacara tradisi Mondhosio berlangsung pada jam 07.00 pagi sampai dengan 16.00. Pada jam 07.00 pagi, para sesepuh adat dan tokoh masyarakat membawa seekor kambing kendit dan seekor ayam ke Punden Bakpatokan untuk disembelih sebagai bahan sesaji. Kambing yang digunakan bukan kambing sembarangan, tetapi kambing yang berwarna putih dan hitam tetapi ditengah perutnya terdapat sabuk yaang berwarna putih atau hitam.

Pukul 10.00, semua bahan sesaji di siapakan di dalam Punden Bakpatokan. Kemudian pukul 13.00 diperdengarkan “Gendhing Manyar Sewu”. Pada pukul 16.00 upacara mondhosio akan segera berlangsung yang kemudian dipimpin oleh para sesepuh adat. Ada beberapa proses yang digelar pada tradisi ini pertama yaitu dengan pertunjukkan kelompok seni reog. Kelompok yang berpartisipasi tidak hanya dari karangayar, melainkan ada juga yang dari Ponorogo, Solo, dan beberapa kota lainnya. Beberapa pelaku kesenian Reog berkumpul di sini untuk memeriahkan pagelaran mondhosio. Di antara paguyuban itu ialah Reog Gunung Lawu, Singo Gilang, Singa Pancat Mulya, dan Singa Manggolo Yudha. ${ }^{12}$

Kelompok-kelompok reog itu mulai membuka pintu masuk dusun sampai ke lokasi yang jarak tempuhnya lebih dari 200 meter. Mereka tidak hanya berjalan sembari menampilkan musik yang khas diikuti dengan memainkan reog. Ketika rombongan reog sudah sampai di tempat upacara, rombongan akan duduk santai di sebuah bangunan kecil yang biasanya dinamakan Dusun Pancot adalah Cungkup Watu Gilang. Cungkup ini digunakan untuk menyiram air badheg sudah disiapkan.

Sebelum acara puncak itu berlangsung, air badheg ini kemudian disiramkan ke Batu Gilang dan warga yang hadir. Hal ini bertujuan agar orang yang memiliki sifat lengket (buruk) pada dirinya hilang. Tetapi para warga banyak yang menghindar karena baunya tidak enak. Air badheg yang disiram ke Batu Gilang itu karena sempurnanya roh Prabu Boko dulunya minta disiram dengan air badheg yang memiliki simbol sebagai peringatan bahwa air tersebut adalah air yang memabukkan. Di sini, ada makna bahwa masyarakat tidak boleh meminum minuman berakohol apalagi minuman yang memabukkan.

\footnotetext{
12 Observasi Lapangan pada tanggal 10 Maret 2020.
} 
Kemudian acara pun selesai dilanjutkan dengan acara nadzar, yaitu menerbangkan ayam. Biasanya orang tersebut melepaskan sepasang ayam jantan dan betina. Jika ada orang yang bernadzar dirinya naik pangkat, maka ia akan melepaskan satu pasang ayam. Ada juga mahasiswa yang bernadzar lulus kuliah akan melepaskan sepasang ayam. Jadi yang nadzar ini berlaku untuk siapa saja, bukan hanya dari warga Dusun Pancot.

Pada pelaksanaan acara ini, gamelan yang ditabuh merupakan gamelan khusus, yang dinamai gamelan 'kyai tokprol'. Sedangkan gendhing yang akan dinyanyikan diantaranya 'kusoroso', yang memiliki makna untuk doa agar masyarakat Dusun Pancot terhindar dari penyakit dan sehat. Kemudian dilanjutkan dengan 'gendhing ladang wilujeng' yaitu gendhing yang bertujuan untuk meminta satu harapan pada Tuhan agar warga Dusun Pancot selalu dihindarkan musibah dan didekatkan pada keselamatan. Setelah itu dilanjutkan dengan 'gendhing ladang dwi rahayu', yaitu wujud ladang mengingat-ingat agar masyarakat selalu ingat kepada Tuhan, sang pencipta alam dan para arwah leluhur. Tabuhan terakhir yaitu 'gending gangsaran'yang memiliki arti doa untuk sebuah pengharapan. Pengharapan ketika acara mondhosio dimulai tidak ada kendala apapun dan cita-cita yang diinginkan masyarakat Dusun Pancot tercapai. ${ }^{13}$

Tradisi Mondhosio adalah suatu acara yang dilakukan pada hari Selasa Kliwon setiap tujuh bulan sekali atau satu tahun dua kali. Acara ini merupakan ungkapan rasa syukur terhadap Tuhan yang telah melimpahkan kenikmatan kepada masyarakat yang telah disuburkan tanahnya yang menjadi sebuah wisata ataupun lahan yang menghasilkan berbagai rezeki. Dengan adanya kegiatan ini, masyarakat menjadi guyup rukun. Masyarakat yang saling menghormati antara satu dengan masyarakat yang lain. ${ }^{14}$

\section{Makna Simbolik Tradisi Mondhosio}

Manusia yang dikenal dengan animal symbolicum, tidak pernah dilepaskan dari symbol atau tanda yang ada di sekitar mereka. Dengan tanda itulah mereka berkomunikasi dan menyampaikan pesan. ${ }^{15}$ Simbolisme juga merupakan suatu hal yang menonjol yang ada dalam tradisi atau suatu adat istiadat. Begitu juga dalam pelaksanaan tradisi mondhosio ini. Ada sejumlah symbol yang dapat dianalisa dari setiap sesaji atau uborampe yang diadakan. Simbolisme dalam masyarakat tradisional disamping membawa pesan kepada generasi ke generasi berikutnya, selalu berkaitan dengan tingkat religiusitas. ${ }^{16}$

\footnotetext{
13 Observasi Lapangan pada tanggal 10 Maret 2020.

14 Diolah dari hasil wawancara, Selasa 10 Maret 2020.

${ }^{15}$ Daniel Chandler, Semiotics (New York: Routladge, 2007).

${ }^{16}$ Budiono Herusatoto, Simbolisme Jawa (Yogyakarta: Ombak, 2008).
} 
Tradisi di setiap daerah itu memiliki keanekaragaman uborampe yang berbeda-beda. Uborampe atau perlengkapan yang terdapat dalam upacara-upacara acara tradisi bisa jadi memiliki kelengkapan yang sama, tetapi memiliki makna dan simbol yang berbeda. Tradisi mondhosio ini memiliki uborampe yang sedikit berbeda dengan tradisi yang lain di antaranya kemenyan, lampu uripurip, badheg, sesajen, dan berebut ayam jantan dan betina. Kesemuanya memiliki makna dan simbol untuk mendekatkan diri kepada Tuhan dan mengahargai para leluhur.

Di antara uborampe yang harus ada dalam pelaksanaan tradisi mondhosio yakni kemenyan. Kemenyan ini diyakini sebagai penyambut arwah. Dalam hal ini, masyarakat menyiapkan bau wangiwangian seperti kemenyan, dan bunga agar arwah yang sudah meninggal tidak mengamuk. Selain itu, kemenyan ini merupakan wujud ucapan tanda rasa menghormati arwah yang sudah meninggal.

Selanjutnya ada lampu urip-urip, merupakan lampu yang digunakan untuk ditaruh di tempattempat yang dianggap keramat. Makna dari lampu urip-urip ini adalah lambang hubungan manusia dengan yang ghoib yaitu kepada Tuhan. Lampu urip-urip ini dinyalakan di tempat yang dianggap keramat hingga beberapa hari, karena memiliki simbol bahwa Tuhan itu hanya satu dan manusia harus ingat kepadaNya selalu.

Badheg digunakan untuk menyiram 'Batu Gilang', yang memiliki makna sebuah peringatan bahwa air itu memabukkan, air yang mengandung alkohol, warga tidak boleh minum air yang memabukkan karena air itu adalah air yang haram dan dilarang Tuhan. Seseorang yang meminum air badheg ini akan mambuk. Jika sudah mabuk, maka ia akan melakukan hal-hal tercela sebagaimana Prabu Boko yang mabuk dalam urusan dunia dan pribadinya. Sehingga melakukan apapun yang melanggar kemanusiaan.

Selain itu, ada aneka sesajen yang ditampilkan dalam upacara mondhosio ini, seperti sego golong, tumpeng, sego takir, ingkung, jajan pasar, gandhik, jodok dan senthir, dan kembang berupa. Pertama, sego golong merupakan nasi yang dibentuk bulan seperti bola tenis dan disajikan dalam tujuh pasang atau empat belas butir. Sego golong ini diadakan dengan maksud sebagai penghormatan kepada Tuhan yang menciptakan bumi seisinya. Sego golong pithung jodho memang sangat spesifik dan menjadi semacam uborampe wajib dalam menggelar acara upacara ritual. Dengan uborampe ini diharapkan agar orang yang membuat slametan dalam menapaki setiap perjalanan waktu untuk mengarungi kehidupannya selalu selamat dan berhasil meraih cita-cita.

Kedua, tumpeng yang melambangkan suatu cita-cita atau tujuan yang mulia yaitu seperti gunung yang memiliki sifat besar dan puncaknya menjulang tinggi. Dalam tradisi mondhosio ini menggunakan tumpeng alus yang berupa nasi putih yang berbentuk kerucut atau gunung tanpa diberi lauk pauk. Tumpeng Alus memiliki makna sebagai permohonan kepada Tuhan agar masyarakat yang 
sedang mengikuti upacara tradisi mondhosio agar selalu dalam lindungan Tuhan dan selamat sampai dengan selesainya acara.

Ketiga, takir atau wadah yang digunakan untuk meletakkan nasi yang berisi lauk pauk seperti serondeng, sayur lombok, kerupuk udang, kacang tanah. Takir ini terbuat dari daun pisang yang dibentuk pesegi dan sebelah kiri dan kanan diberikan jiting. makna dari takir itu sendiri adalah penyerahan, arti penyerahan itu sendiri adalah penyerahan seseorang abdi kepada pemberian atau penyerahan anak kepada bapaknya. Dalam hal ini maka orang yang harus menyerahkan dirinya kepada Tuhan dan selalu tunduk dan patuh kepadanya.

Keempat, ingkeung yang berupa ayam kampung yang dimasak utuh dan ayamnya dibanda atau dibelenggu. Makanan ini dimaknai dengan seorang bayi yang masih di dalam kandungan dan belum memiliki kesalahan satu pun atau dapat disebut bayi yang masih suci. Dapat dimaknai juga sebagai sikap yang pasrah kepada Tuhan terhadap apa yang telah ditakdirkan. Makna lainnya yaitu untuk mensucikan orang yang mengikuti tradisi mondhosio sekaligus sebagai simbol permohonan ampun seluruh penduduk desa dan dijauhkan dari segala dosa dan kesalahan.

Kelima, tukon Pasar atau uborampe yang berisi aneka jajanan tradisional. di dalamnya berisi roti, tape, kacang, gethuk, dan jajanan lima ratusan. Makna dari jajan pasar ini adalah semua memohon dengan lengkap kepada Tuhan agar dikabulkan permohonnya dan menjadikan agar manusia itu selalu bersyukur atas pemberian Tuhan.

Keenam, gandhik atau makanan yang terbuat dari beras yang kemudian dikepeli seperti punggung sapi, terdiri atas dua macam warna dan rasa, yaitu warna putih dan merah yang diberi gula jawa. Memiliki simbol membuang yang sia-sia atau sengkolo, dosa dan kejahatan. Ketujuh, jodog dan senthir yang berupa alat penerang, terbuat dari botol yang diisi dengan minyak tanah dan kemudian atasnya diberi sumbu dan dinyalakan. Makna dari simbol ini adalah sebagai simbol penerang agar arwah leluhur yang sudah meninggal dunia itu selalu berada di alam yang terang dan agar tidak tersesat. Kedelapan, kembang berupa yang memiliki makna harum, memiliki nilai-nilai mistis seperti hadirnya roh halus yang perlu disambut dengan wangi-wangian atau hal yang berbau harum. Jumlahnya ganjil, bertujuan mengagungkan atau mengesakan Sang Pencipta.

Sementara itu, satu hal yang menjadi khas dalam acara mondhosio ini adalah fenomena lempar ayam, sebagaimana disinggung di muka. Ada banyak simbol yang muncul di dalam pelaksanaan ini, misalnya ayam yang memiliki makna sebagai pelepasan arwah-arwah kesempurnaan. Ayam yang digunakan adalah ayam jawa, karena memiliki simbol sebagai bahwa hidup itu harus dengan kerja keras, ulet dan tangkas, selalu istiqomah dalam bekerja ataupun mendekatkan diri kepada Tuhan. Ketika Ayam masih hidup, ayam mencari makan sendiri, ulet, dan bekerja keras. Acara pelepasan terdiri dari sepasang ayam jantan dan betina, lambang 
keberagaman manusia yang hidup berpasang-pasangan, bersuku-suku untuk memperbaiki keturunan. Untuk itu, manusia dilarang untuk saling merendahkan dan hendaknya dapat hidup berdampingan. Ayam tersebut kemudian diterbangkan kea tap dengan maksud melebur kesalahankesalahan antar sesama warga. Dengan begitu, maka acara ini juga berupa wujud dari saling memaafkan dan menyadari bahwa manusia memang tidak luput dari kesalahan.

\section{Kesimpulan}

Tradisi upacara bersih desa mondhosio merupakan kegiatan warisan leluhur yang masih dilestarikan hingga kini. Acara ini diselenggarakan sebagai perwujudan rasa syukur atas nikmat Tuhan. Acara ini menjadi menarik dengan adanya tradisi lempar ayam yang syarat makna. Meski terkesan klenik, karena memuat sejumlah sesajen yang dimunculkan, tapi di dalamnya ada istilah nazdar. Hal ini menunjukkan bahwa ada nuansa islami di dalamnya. Selain itu, tradisi mondhosio memiliki makna dan simbol yang beragam dan tidak dimengerti oleh masyarakat daerah lain, apalagi generasi bagi generasi muda. Sementara di dalam pelaksanaan kegiatan ini banyak sekali kearifan-kearifan yang dapat ditemukan, misalnya tentang sopan santun, menjunjung tinggi adab dan perilaku terpuji, dan lain sebagainya. Sehingga tradisi semacam ini perlu terus digali sebagai salah satu kekayaan Indonesia untuk dikenal dan dilestarikan, sebagai cerminan budaya bangsa yang majemuk.

\section{Referensi}

Anam, Choerul. “Tradisi Sambatan Dan Nyadran Di Dusun Suruhan.” sabda 12 (2017): 77-84. Chandler, Daniel. Semiotics. New York: Routladge, 2007.

Chatrin, Sherly. "Tinjauan Filsafat Kebudayaan Terhadap Upacara Adat Bersih Desa Di Desa Tawun, Kecamatan Kasreman, Kabupaten Ngawi Jawa Timur." Jurnal Filsafat UGM 27, no. 1 (2017): 30-63.

Fauzan, Rikza, and Nashar. "Mempertahankan Tradisi, Melestarikan Budaya; Kajian Historis Dan Nilai Budaya Lokal Kesenian Terebang Gede Di Kota Serang." Candrasangkala 3, no. 1 (2017): 1-3.

Fitriana, Rita. "Bentuk Dan Fungsi Kesenian Raksasa Dalam Upacara Bersih Desa Di Desa Salamrejo Kecamatan Binangun Kabupaten Blitar.” Institut Seni Indonesia, Surakarta, 2017. Haidar, M. Aly. "Pergeseran Pemaknaan Ritual 'Merti Dusun'; Studi Atas Ritual Warga Dusun Celengan, Tuntang, Semarang." Al A'raf: Jurnal Pemikiran Islam dan Filsafat 13, no. 1 (2016): $1-24$. 
Herusatoto, Budiono. Simbolisme Jawa. Yogyakarta: Ombak, 2008.

Rizkiawan, Idham. "Faktor-Faktor Yang Mempengaruhi Persepsi Masyarakat Tentang Makna Sesajen Pada Upacara Bersih Desa.” Boga 5, no. 2 (2017): 11-17.

Safrudin Aziz. "Ada, Tradisi Pernikahan Adat Jawa Keraton Membentuk Keluarga Sakinah.” kebudayaan Islam 15, no. 1 (2017): 22-41.

Sobirin, Ali. Studi Pelaksanaan Upacara Bersib Desa Pranggang Kecamatan Plosoklaten Kabupaten Kediri, 2017.

Sugiyono. Metode Penelitian Kuantitatif, Kualitatif, Dan R \& D. Bandung: Alfabeta, 2016.

Yusof, Abdullah. "Relasi Islam Dan Budaya Lokal Studi Tentang Tradisi Nyadran Di Desa Sumogawe Kecamatan Getasan Kabupaten Semarang.” Kontemplasi 04, no. 01 (2016): 5355. 